\section{Psychiatric liaison services to the Scottish Liver Transplant Unit}

Sir: We were pleased to read the paper by Mitchell et al (Psychiatric Bulletin, January 1997, 21, 6-9) but felt that some points deserve fuller discussion.

Paracetamol overdose and pre-transplant assessment. Patients who have taken a serious overdose and are transferred to the Liver Unit have only a short period of time before their conscious level may alter due to liver failure. It may be difficult to arrange continuous senior psychiatric input over a 24-hour period and we have some doubts as to the contribution this can make to the decision on transplant suitability as such assessments may be rushed and changes in conscious level may affect the mood state and cognition of the patient, leading to inaccurate responses regarding present and future suicidal intent. A fuller assessment is needed prior to transfer to the Liver Unit. This should include assessment by a local senior psychiatrist, collection of information from next of kin, general practitioner and all available notes. Known suicide risk factors and outcome predictors could be identified, which could be added to the information available to the liaison psychiatrist. As there are a range of other poor outcome predictors such as drug abuse, serious and intractable mental illness, which increases suicide risk (ranging from schizophrenia, bipolar affective disorder, chronic depression) and certain types of personality disorder it may be difficult to fully assess these factors within the often short time frame before liver failure.

Alcoholic liver disease. There is a need for earlier and more comprehensive psychiatric assessment before transplant, as witnessed by the increasing number of patients being considered for a second transplant, or who have continued to misuse alcohol after transplant. It is difficult to assess the true motivation of such patients to abstain from alcohol and likely relapse triggers. More extended assessments of suitability and the greater use of psychological therapies may be required e.g. concentrating on widening of the social network to non-alcohol related activities and assessment of the patient's strategies to cope with 'high risk' situations are necessary. We have experimented with the use of pre-transplant 'contracts' agreed with the patient, which include the requirement of psychological therapy e.g. using problem solving approaches to deal with the above risk factors.

Funding. Our experience has been that input from other disciplines including liaison nursing, occupational therapy and social work and urgent in-patient treatment have been needed and this has prompted a re-evaluation of the resources needed for our service. In view of the often supraregional nature of such services there would appear to be a case for direct central funding of such services and adequate provision of multi-disciplinary liaison psychiatry teams.

SEAN LYNCH, Senior Lecturer in Psychiatry; and SUKH LALLY, Senior House Officer in Liaison Psychiatry, St James's University Hospital, Leeds

\section{The rush for the MRCPsych?}

Sir: The Calman reforms have introduced a structured programme of psychiatric training which reduces the overall duration of psychiatric training. After four years of basic specialist training in the combined old senior house officer (SHO) and registrar grades, trainees need possession of the MRCPsych to progress to three years' of higher specialist training in the Specialist Registrar grade.

Current MRCPsych examination entry criteria requires one year's experience in psychiatry before sitting the Part 1 and a total of three years' experience before sitting the Part 2 examination. Within the new Calman structure the maximum time for trainees to progress from Part 1 to Part 2 examinations is approximately 30 months. This is the difference between the maximum time available for basic training ( 48 months) and the earliest possible date for success in the Part 1 examination near the end of the third, six-month SHO post (18 months). As the Part 2 can only be attempted after three years' training most trainees will have only two attempts at this examination in the last year of basic training, unless they are eligible to include previous non-psychiatric posts as suitable experience. There will be no time for the five attempts at the Part 2 examination that the College currently allows without breaching the structure by which the duration of training has been reduced.

We analysed the time current trainees took between passing the two parts of the examination by scrutinising previous Part 1 pass lists for those candidates successful at the Autumn 1995 Part 2 examination. The date of passing was successfully traced for 131 of the 154 (85\%) candidates. For $23(18 \%)$ duration was longer than the 30 month threshold. This significant proportion (which will be larger if untraced candidates are still attempting the examination) will run out of time in basic training. Current trainees will have to progress through examinations quicker than their predecessors. This will become the rush for the MRCPsych. We fear that a broad education in psychiatry will be sacrificed in the sole pursuit 
of examination success. We would welcome guidance from the College on the content and duration of local MRCPsych courses within Calman training.

HARVEY REES Senior Registrar in Old Age Psychiatry. St Martin's Hospital, Midford Road,
Bath BA2 5RP; ROGER DENNY Specialist Registrar in General Adult Psychiatry, Cossham Hospital, Lodge Road, Kingswood, Bristol BS15 ILF, and BRIAN ROBINSON Consultant Psychiatrist and Regional College Tutor Assessment and Training, 1 Colston Fort, Montague Place, Kingsdown, Bristol BS2 5UB

\section{Prevention of Anxiety and Depression in Vulnerable Groups \\ Joanna Murray}

The scope of this review, commissioned by the Department of Health, is the common mental disorders of anxiety and depression occurring in adults in the community. It considers the possibilities for prevention in primary care. This combination of basic conceptual and research information provides a practical framework of preventive strategies for the primary care team. Social factors in aetiology are examined in detail, and epidemiological data is used to consider vulnerability factors and to identify high risk groups. There is also a thorough review of risk for common mental disorders.

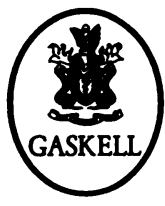

$\bullet £ 7.50 \bullet 112 p p . \bullet 1995 \bullet$ ISBN 0902241877

Available from bookshops and from the Publications Department, Royal College of Psychiatrists, 17 Belgrave Square, London SW1X 8PG (Tel. 0171-235 2351 extension 146) 